\title{
Planarization and fabrication of bridges across deep grooves or holes in silicon using a dry film photoresist followed by an etch back
}

\author{
V L Spiering, J W Berenschot and M Elwenspoek \\ MESA Research Institute, University of Twente, PO Box 217, 7500 AE Enschede, \\ The Netherlands
}

Received 14 December 1994, accepted for publication 4 January 1995

Abstract. A technique is presented that provides planarization after a very deep etching step in silicon. This offers the possibility for not only resist spinning and layer patterning but also for realization of bridges and cantilevers across deep grooves or holes. The technique contains a standard dry film lamination step to cover a wafer with a $38 \mu \mathrm{m}$ thick foil. Next the foil is etched back to the desired thickness of a few micrometres. This thin film facilitates resist spinning and high-resolution patterning. The planarization method is demonstrated by the fabrication of aluminium bridges across a deep groove in silicon.

\section{Introduction}

The design of micromachined devices is often limited by the impossibility of layer patterning by resist spinning on a wafer surface containing large steps in height. The standard resist spinning method needs a flat surface for coverage with a uniform layer thickness. This means that after etching deep grooves or holes in a wafer, it is difficult to pattern existing or new deposited layers. Usually one tries to carry out the deposition and patterning of all layers first and finish the process with the deep etch step. This, however, is not always possible because technology- and material-based constraints play a role in the possibilities of chronology of the process steps. If, for example, a deep etched groove is used as a mould to shape a structure, the chronology cannot be reversed: the deep etch step has to be followed by the deposition of the structure material.

Alternative methods to apply photoresist are dipping, spraying, or producing dry resist coatings by vacuum deposition, plasma deposition, or adsorption, eventually followed by dry development (in situ radiation deposition) $[1,2]$. Furthermore, the shadow mask technique can be used to deposit patterns on wafers with deep etch holes. Although with these methods patterning of the wafer surface is no problem, it is not possible to create bridges across the etch holes. Another planarization technique is filling the holes with an organic material, e.g. a polymer, eventually followed by a heating step. The flatness of the structures across the holes will then be determined by the shape of the planarized filling material, which can be a serious restriction in the case of very deep etch holes.

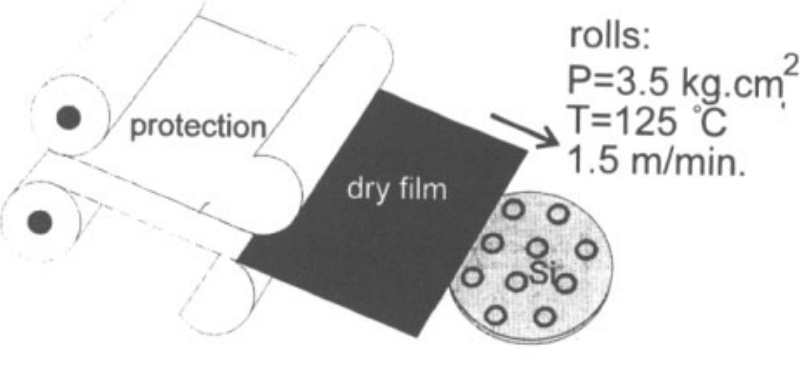

Figure 1. Two-roll laminator set-up: the substrate is sandwiched between two dry films.

Finally, an alternative method is the sacrificial wafer bonding method [3]. The sacrificial wafer bonding technique contains a wafer bond step followed by an etch back to a thin stop layer. With this method planarization and fabrication of bridges across deep grooves are possible. Results of polymer bonding followed by dry etching and anodic combined with $\mathrm{KOH}$ etching were presented before $[3]$.

A simpler faster technique is presented here. It uses the lamination of a thin photosensitive foil, which is uniformly etched back to a thickness of typically a few micrometres. The depositing and patterning of new layers is then possible. Bridges and cantilevers can be fabricated across deep grooves or holes by this method. 
1

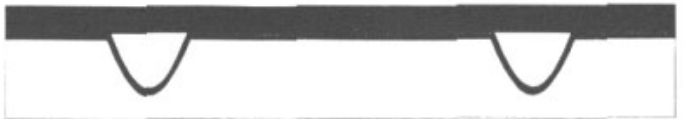

2

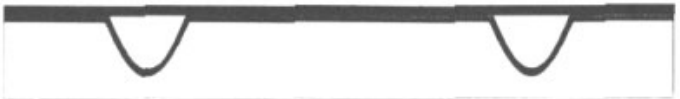

3

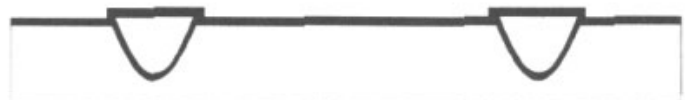

a

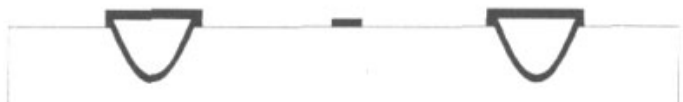

b

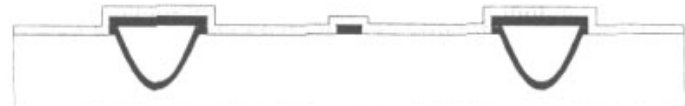

4

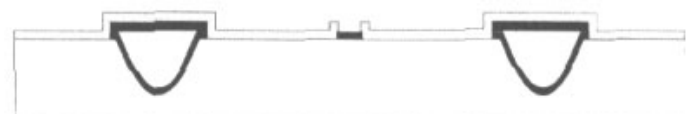

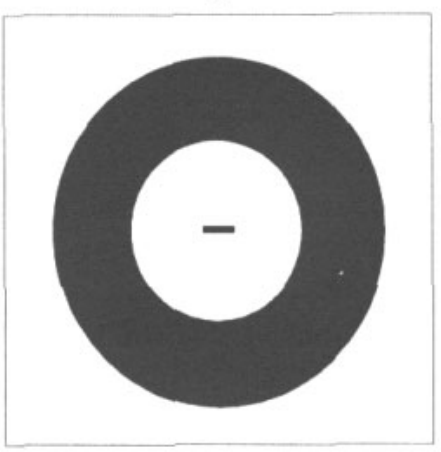

4

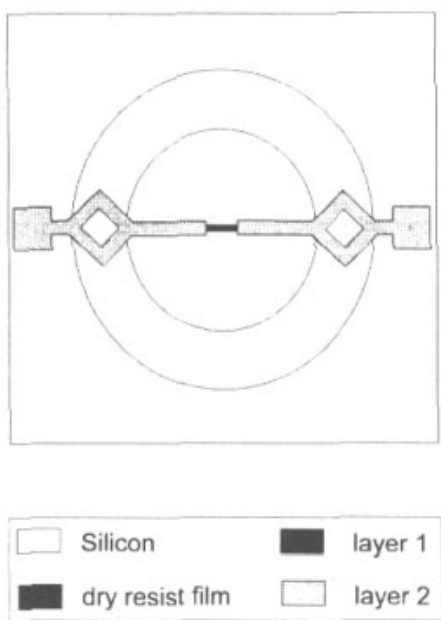

Figure 2. (a) Main steps of the dry film planarization process: 1, on top laminating of the dry film; 2, etching down of the dry film to a few:micrometres; 3 , patterning of the dry film; a, original layers (e.g. layer 1) can be patterned; b, new layers (layer 2) can be deposited and patterned; 4 , removing of the dry film ( $a$ and $b$ are device process steps). (b) Top view of a device after step (a) and step (4) of the dry film planarization process.

\section{Dry film photoresist}

Photoresists in film form are widely applied in printed circuit fabrication because they are frequently more convenient to apply and provide higher yields than liquid photoresists [4]. Applications in the field of microtechnology have been limited so far because the thickness of the resist layer in commercially available dry films lies between 15 and $75 \mu \mathrm{m}$. Therefore this technique without adaptations cannot be used to define spacings smaller than circa $25 \mu \mathrm{m}$.

The applied dry film Ordyl AP838 consists of a $38 \mu \mathrm{m}$ thick resist sheet, covered by a "polyester protection film. This dry film is extremely pliable, which enables tenting of large tooling holes. In the used two-roll laminator setup the substrate is sandwiched between two dry films, at a pressure of $3.5 \mathrm{~kg} \mathrm{~cm}^{-2}, 125^{\circ} \mathrm{C}$ roller temperature, and a speed of $1.5 \mathrm{~m} \mathrm{~min}^{-1}$, see also figure 1 . Commonly the resist is exposed with UV light and the polyester cover sheet is removed afterwards. The AP838 resist can be developed and stripped in alkaline solutions. However, with this procedure the resolution will still be poor. That is why an alternative procedure was developed. The goal was to increase the resolution and to open the possibility to fabricate bridges and cantilevers across deep grooves or holes. The main step of the procedure is the uniform etch back of the dry film to a desired thickness of a few micrometres. The direct lamination of a very thin film causes difficulties in adhesion and strength [5]. Note that the etch back is done after UV exposure without a mask, because after exposure an improved bond quality between film and substrate was observed.

To achieve single side lamination the film is removed from one side (before UV exposure). An alternative method is to position the silicon wafer substrates on a square glass plate and carry out the lamination. After cutting out the wafer from the sheet at the top side, a single-sided dry film-covered wafer is obtained.

Beside planarization, other application areas of the dry films are shadow masking [6] and thick resist patterning with perpendicular side walls [7]. This pattern could be applied as a mould for electroplating. These applications will not be discussed here.

\section{Fabrication process}

Figure 2 shows how the planarization process can be applied to fabricate bridges on a wafer with deep grooves. The process starts with the lamination of the dry film on top of a wafer containing deep grooves. The most difficult 
step is the uniform etch down (2). This was done in a reactive ion etcher with a $\mathrm{CHF}_{3} / \mathrm{O}_{2}$ plasma. The $\mathrm{CHF}_{3}$ is added to stimulate underetching. In that way a very rough etched surface, sometimes called grass, is prevented [7,8]. To increase the uniformity in etch rate, the whole bottom electrode was covered with a dry resist film, with the wafer located in the centre. This resulted in a decrease of etch rate (from 1.1 to $0.45 \mu \mathrm{m} \mathrm{min}^{-1}$ ), but the uniformity was improved, so that differences in local etch rates were less than $3 \%$. The patterning of the dry film (step 3 ) is done by reactive ion etching using an aluminium mask. To obtain steep side walls an anisotropic etch process in a pure $\mathrm{O}_{2}$ plasma is applied (etch rate $0.53 \mu \mathrm{m} \mathrm{min}^{-1}$ ) [7].

\section{Experimental results}

The technique has been demonstrated with a process that results in aluminium bridges with a resist foundation across a deep groove in silicon. The process steps are:

- dry film lamination

- 80 s UV-exposure $\left(15 \mathrm{~mW} \mathrm{~cm}^{-2}\right)$

- remove cover sheet (peel off)

- etch back to desirable thickness (RIE): $\mathrm{CHF}_{3}: \mathrm{O}_{2}=$ $5: 20 \mathrm{sccm}, 75 \mathrm{~W}, 75 \mathrm{mTorr}, 25^{\circ} \mathrm{C}$, electrode covered with dry film

- $100 \mathrm{~nm}$ Al evaporation

- pattern Al (positive resist Shipley 1813)

- anisotropic etch of the dry film (RIE): $\mathrm{O}_{2}=20 \mathrm{sccm}$, $75 \mathrm{~W}, 75 \mathrm{mTorr}, 25^{\circ} \mathrm{C}$, electrode covered with dry film

Figure 3 shows the resulting aluminium bridge across the groove. For this structure a dry resist film was laminated and etched back to about $7 \mu \mathrm{m}$. This result shows that it is possible to make electrical contacts across a deep etch pit.

The dry film lamination, in combination with the dry etch back, will be applied in a membrane pressure sensor containing a deep corrugation [3], as outlined in figure 4. The corrugation is added to reduce package stresses and to obtain a residual stress relief in the inner circular membrane without losing pressure sensitivity [9]. The planarization technique will be applied to pattern polysilicon strain gauges and to create bridge connections between strain gauges inside the corrugation and bond paths outside the corrugation. The resist laminate will be completely removed afterwards.

\section{Conclusions}

A flexible technique using a dry resist film for planarization after a very deep etching step is demonstrated. With this technique, not only do resist spinning and layer patterning become possible, but also the fabrication of bridges and cantilevers across deep grooves or holes. Because of its simplicity and usefulness, the technique is very suited for application in microelectromechanical systems. The method was demonstrated with the fabrication of aluminium bridges across a deep groove in silicon. Future research will focus on deposition of thinner dry films.
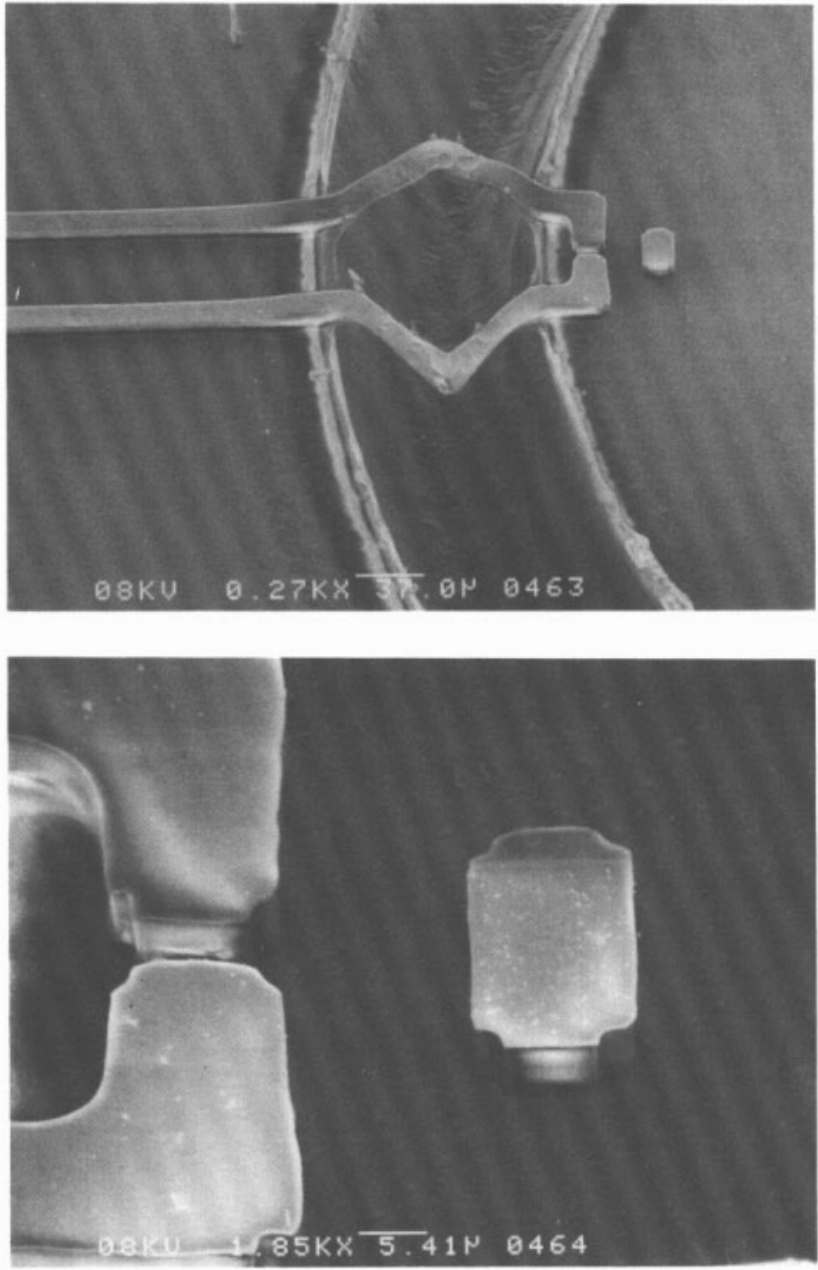

Figure 3. SEM photograph of a realized aluminium bridge across a deep groove in silicon.

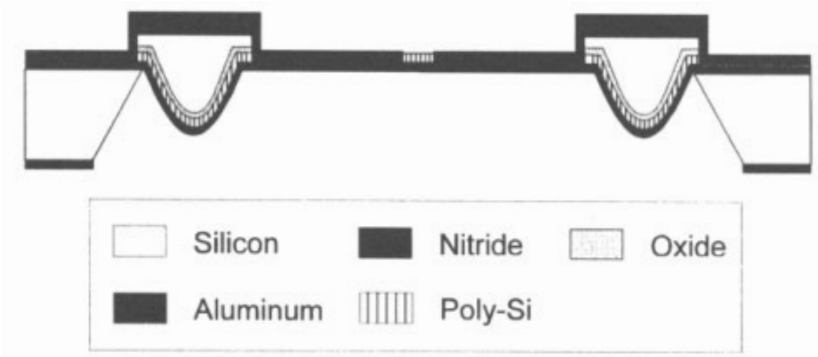

Figure 4. Basic outline of the cross-section of the membrane-pressure sensor containing a deep corrugation.

\section{Acknowledgments}

These investigations in the programme of the Foundation for Fundamental Research on Matter (FOM) have been supported by the Netherlands Technology Foundation (STW). The Group Micro Technique from the University of Delft is acknowledged for introducing us to the dry film technology. Mr J H Berton is thanked for carrying out the dry film laminations for this research.

\section{References}

[1] d'Agostino R, Morita S and Hattori S (ed) 1990 Plasma Deposition, Treatment, and Etching of Polymers (San Diego: Academic) pp 424-43 


\section{L Spiering et al}

[2] Moreau W M 1988 Semiconductor Lithography, Principles, Practices, and Materials (New York: Plenum)

[3] Spiering $V$ L, Berenschot J W, Elwenspoek $M$ and Fluitman J H J 1994 Low temperature sacrificial wafer bonding for planarization after very deep etching 7th IEEE Workshop on Micro Electro Mechanical Systems (MEMS'94 (Oiso, Japan, Jan) pp 69-74

[4] Kelemen D G 1976 Dry film photoresists in microelectronics Solid State Technol. Aug, 37-48

[5] Mr Gilsing, Du Pont Electronics, Den Bosch. The Netherlands

[6] Burger G J, Smulders E J T, Berenschot J W, Lammerink T S J, Fluitman J H J and Imai S 1994 High resolution shadow mask patterning in deep holes and its application to an electrical wafer feed-through Int. Conf. Solid-State
Sensors and Actuators (Transducers '95), Stockholm, Sweden, June)

[7] Jansen $H \mathrm{~V}$, de Boer $M \mathrm{~J}$, Legtenberg $\mathrm{R}$ and Elwenspoek $M$ 1995 The black silicon method: a universal method for determining the parameter setting of a fluorine-based reactive ion etcher in deep silicon trench etching with profile control J. Micromech. Microeng. 5

[8] Legtenberg $R$, Jansen $H$, de Boer $M$ and Elwenspoek $M$ 1995 Anisotropic reactive ion etching of silicon using $\mathrm{SF}_{6} / \mathrm{O}_{2} / \mathrm{CHF}_{3}$ gas mixtures $J$. Electrochem. Soc. accepted for publication

[9] Spiering V L, Bouwstra S, Burger J F and Elwenspoek M 1993 Membranes fabricated with a deep single corrugation for package stress reduction and residual stress relief $J$. Micromech. Microeng. 3 243-6 